\title{
Pregnancy Intentions and Its Associated Factors Among Married Women in Resunga, Gulmi, Nepal
}

Rita Karki ( $\square$ ritakarki518@gmail.com )

One Heart Worldwide

\section{Surendra Maharjan}

Tokyo Metropolitan University: Shuto Daigaku Tokyo

\section{Ganesh Khatiwada}

Central Department of Population Studies, Tribhuvan University

Junu Shrestha

Tribhuvan University Institute of Medicine

Research article

Keywords: pregnancy intentions, married women, abortion

Posted Date: October 21st, 2020

DOl: https://doi.org/10.21203/rs.3.rs-93497/v1

License: (c) (i) This work is licensed under a Creative Commons Attribution 4.0 International License. Read Full License 


\section{Abstract}

\section{Background}

Pregnancy intention refers to a women's thinking at the time she became aware that she was pregnant. Pregnancy intentions can be categorized as intended and unintended. It is an important public health concern in every corner of the world, especially in developing countries. The study was carried out with an objective of determining the pregnancy intentions among married women in Resunga municipality, Gulmi, Nepal and test the association of pregnancy intentions with various socio-demographic, and reproductive health-related variables.

\section{Methods}

The community based cross-sectional study design was used to achieve the objective of the study. Married women of reproductive age of the Resunga municipality, Gulmi were selected and a multistage random sampling technique was adopted. Total 406 participants were involved in this study. Pretested semi-structured interview schedule adapted from Demographic and Health Survey of Nepal was used for data collection. All the statistical tests were performed in SPSS, version 25.0. The $p$-value was set at 5\% level of significance. Descriptive and data exploratory analysis were performed. Bivariate and multivariate logistic regression analysis technique were conducted to explore the association between pregnancy intentions and predictor variables.

\section{Results}

The study showed that out of total 410 pregnancies, 248 (60.5\%) pregnancies were unintended, of which 78(19.05\%) were unplanned and 170 (41.5\%) were ambivalent. The remaining 162 (39.5\%) pregnancies were considered intended. The chi-square analysis and bivariate analysis showed that women age, socioeconomic status, husband opposition, methods used before pregnancy, and intention of using contraception in the future were significantly associated with pregnancy intentions. When these variables were subjected for multivariate analysis, only socioeconomic status, and method of family planning used before pregnancy were found to be significantly associated with pregnancy intentions.

\section{Conclusions}

The study showed that unintended pregnancy is very high. The factors that were found to be associated with an unintended pregnancy were socioeconomic status and method of family planning used before pregnancy. The findings of this research work could be useful while providing different reproductive and family planning related services to women by considering predictors of unintended pregnancy that might increase planned pregnancy ultimately.

\section{Background}


Nepal is a tiny land-locked country that lies in the laps of the Himalayas with an area of $147,516 \mathrm{~km}^{2}$ with a population of $26,494,504$, and a population growth rate of $1.35 \%$ per annum. Women comprise more than half of the population, i.e., $13,645,463$ (i.e. $51.5 \%$ ). Among the female population, nearly half of the women (i.e. $47.78 \%$ ) are in the reproductive age group (15-49 years) [1]. The total fertility rate of the country is nearly stagnated at 2.3 in the 2016 Nepal Demographic Health Survey (NDHS) from 2.6 in the 2011 NDHS, which is still high. NDHS 2016 shows that approximately 53\% of currently married women use a method of family planning, and $24 \%$ have an unmet need for family planning services. In Nepal, 323,100 women had undergone abortion in 2014 , and the abortion rate was 42 per 1,000 women of reproductive age. Overall, half $(50 \%)$ of all pregnancies were unintended [2]. The infant mortality rate was $32 \%$ in NDHS 2016, and maternal mortality was 229 per 100,000 live births in 2011, which is still high [3]. Pregnancy intentions refer to the thinking of women at the time when she became aware that she was pregnant [4]. Pregnancy intention status can be categorized as intended and unintended [5].

It can be measured by asking the pregnancy intentions of women at the time when she became pregnant [6]. Unintended pregnancy is a pregnancy that occurs either earlier than desired (mistimed) or when no more children desire at any time (unwanted) [7]. Unplanned birth is the birth resulting from unintended pregnancy [8]. Unintended births, in contrast to intended births, are less likely to recognize early in pregnancy and receive adequate prenatal care. Likewise, unintended births are less likely to be on breastfeeding of any duration, including exclusive births, and they have to face outcomes such as preterm birth and low birth weight than intended births [5]. The number of pregnancies worldwide is estimated to have been 213 million in the year 2012, and among them, 190 million (i.e. 89\%) occurred in the developing world. Similarly, more than half of all pregnancies occurred (i.e. 56\%) in Asia. Worldwide, $40 \%$ of pregnancies or 85 million pregnancies were unintended pregnancies in 2012 [9]. In the developing world, the pregnancy rate was 143 pregnancies per 1,000 women, whereas in the developed world, it was 90 pregnancies. The rate of unintended pregnancy in the developing world was 57 per 1,000 women, and in the developed world, it was 42 per 1,000 women. The unintended pregnancy rate was $36 \%$ higher in the developing world than in the developed world according to data from 2008. Out of a total 118.8 million pregnancies, 38\% were unintended in Asia in 2008 [10]. In Nepal, the rate of unintended pregnancy was $68 \%$ per 1,000 women of reproductive age, and overall, $50 \%$ of pregnancies were unintended in 2014 [2]. Unintended pregnancy is a worldwide problem that causes serious health, economic and social consequences for women, their family, society and nation [10]. Abortion is the frequent consequence of unintended pregnancy. Sixty-two percent of unintended pregnancies ended in abortion in Nepal in 2014 [2]. Unintended pregnancy is one of the major reproductive health issues and troubling public health problems, creating a socioeconomic burden on individuals and society. It also affects a fertility indicator that reduces quality of life and workforce efficiency [11]. Unintended pregnancy varies by different factors, including maternal age, ethnicity, poverty, and education [12]. The age of the respondents, the total number of births, family planning worker visits and knowledge related to family planning are the major contributing factors to unintended pregnancy [13]. Among multiparous women, those who experience adverse outcomes in the previous pregnancy are more likely to report their pregnancy as unintandad [1 1$] \wedge$ atude annduntad in Ranaladnah chniurg that unmet need for contraception is strongly Loading [MathJax]/jax/output/CommonHTML/fonts/TeX/fontdata.js 
associated with unintended pregnancy. The programme that addresses the unmet need for family planning could be helpful to reduce the prevalence of unintended pregnancy, which consequently reduces the unsafe abortion-related burden of mortalities and morbidities. Family planning programs aimed to reduce the unmet need for family planning that benefits the reduction of the prevalence of unintended pregnancy [15]. A study conducted in Nepal in 2009 identified the age of mother, age at early marriage, media exposure, and knowledge on family planning methods as important contributing factors to unintended pregnancy [16]. More than half of the unintended pregnancies ended in abortion in Nepal. Unsafe abortion is still common in Nepal despite its legalization in 2002 [2].

Worldwide, 40\% of pregnancies or 85 million pregnancies were unintended in 2012 [9]. The rate of unintended pregnancy in the developing world was 57 per 1,000 women, and in the developed world, it was 42 per 1,000 women. Out of a total 118.8 million pregnancies, $38 \%$ were unintended in Asia in 2008 [10]. A cross-sectional study of Pakistan conducted in 2015 showed that $38.2 \%$ of pregnancies were unintended, whereas $61.8 \%$ of pregnancies were intended among 3010 women [17]. In 2014, unintended pregnancy was $68 \%$ per 1,000 women of reproductive age in Nepal. It was highest in the central region $(85$ per 1,000$)$. Half of the pregnancies were unintended, either mistimed or unwanted, with abortion as one of the most frequent consequences of unintended pregnancy. Nationally, $31 \%$ of all pregnancies ended in abortion. This proportion was highest in the central region (41\%). One strategy to reduce abortion is to reduce the level of unintended pregnancy [2]. The study shows that experience of unintended pregnancy is more common among younger women, women who did not complete graduation and those who have higher birth order compared to intended pregnancy. Similarly, women with unintended pregnancy had to face negative birth outcomes, such as preterm birth and low birth weight, which are less likely to breastfeed their child than intended pregnancy [5]. An analytical study based on the NDHS 2011 dataset showed that education status, occupation, parity, media exposure, and autonomy on decision making were key predictors of unintended pregnancy [6]. A study of India based on National Family Health Survey data has shown lower unintended pregnancy among women of higher age, having autonomy and access to mass media and higher education status [18]. Likewise, a study of Southern Ethiopia conducted among married women in 2011 has shown less experience of unintended pregnancy among women who discuss family planning issues with husband and spousal communication was associated with unintended pregnancy with $p<0.05$ value [19]. Similarly, another study of Ethiopia showed that ever used family planning, five or more children were associated with unintended pregnancy [20]. A study conducted in Malawi concluded that pregnancy intention is associated with mother and father age, education, marital status, number of live children, socioeconomic status, birth interval, etc. [21].

Identifying pregnancy intentions during prenatal periods helps to employ careful monitoring of pregnancy that is at high risk for mother and children's health outcomes [22]. Unplanned birth and abortions are the major outcomes of unintended pregnancy. It is considered one of the root causes of women seeking an abortion. In 2014, the abortion rate in the central region was 59 per thousand women of reproductive age, which was higher than the national average of 42 per thousand women of reproductive age $[2,8]$.

Loading [MathJax]/jax/output/CommonHTML/fonts/TeX/fontdata.js ; health problems of reproductive issues. It is

Page $4 / 35$ 
causing a socioeconomic burden to individuals and society, ultimately decreasing the quality of life and workforce efficiency. Therefore, it must be addressed adequately on time [11]. Unintended pregnancy is a contributing factor for maternal and infant mortality, which is still high in Nepal. To reduce maternal and infant morbidity, mortality, and the need for abortion, different types of programs, strategies, plans, and policies should be planned with a focus on the high-risk group. Therefore, it is crucial to identify and understand the factors influencing unintended pregnancy, which is essential to maintain and improve the overall health and wellbeing of women, family, society, and nation [16]. This study validated this information. Similarly, very few studies have been carried out in Nepal regarding pregnancy intentions, with studies studying factors associated with pregnancy intentions taking primary data almost nonexistent. No study has been found on this topic in a similar area of the county. Considering the high unintended pregnancy rate, the proposed study has been forwarded to study the factors associated with it. It is expected that the findings of this study would be useful for academic as well as health management purposes at a different level.

The main aims of this study were to determine pregnancy intentions and assess associated factors among married women in Resunga Municipality, Gulmi, Nepal. We estimated the prevalence of intended and unintended pregnancy, analyzed factors associated with unintended pregnancy, identified spousal communication on contraception between partners for pregnancy planning and identified autonomy to choose contraception.

\section{Methods}

This is a community-based, cross-sectional study. The study employed a quantitative paradigm with the aim of estimating pregnancy intentions and their association with different factors. The sociodemographic and reproductive health variables are shown in Fig. 1.

\section{Participants}

DHS tries to assess the level of unwanted fertility rates by asking a chain of questions among the sample of current pregnancies and births in the five years preceding the survey to women aged $15-49$. This study included married women who became pregnant within the last year, including current pregnancy, as the sampling unit to reduce recall bias to some extent. Women of reproductive age (15-49 years) of the Resunga Municipality, Gulmi, were the study population. The sampling frame was created by preparing the list of all households having women who became pregnant within last year, including current pregnancy, with the help of the Female Community Health Volunteer (FCHV) register, Vitamin A distribution register of respective wards, Antenatal Care (ANC), Immunization register, and Maternal and Child Health $(\mathrm{MCH})$ register.

The sample size was estimated by using a single proportion formula $\left(n=Z^{2} p q / d^{2}\right)[23]$ by making assumptions such as this: taking the prevalence of unintended pregnancy $20 \%(p=20 \%)[24]$ with $q$ as 
$80 \%(q=1-p=100 \%-20 \%=80 \%), 95 \%$ confidence interval $(Z=1.96)$, allowable error taken to be $5 \%(d=$ $0.05)$ that gave $246(n=246)$ and multiplied by design effect by 1.5 that gave $369(n=246 * 1.5=369)$, and adding $10 \%$ non-response, making a final sample size of 406 .

A multistage random sampling technique (probability sampling) was used to select samples of preferred size, as shown in Fig. 2. The Resunga Municipality of Gulmi district was chosen purposively at first, and then 11 wards out of 14 wards were selected using a simple random sampling technique (lottery method). After selecting wards, the required number of women from each ward was calculated using the population proportionate to size technique. A total of 410 married women who became pregnant within the last year, including current pregnancy, were selected from all selected wards by the simple random technique (Lottery).

\section{Data Collection}

The study was conducted in Resunga Municipality, Gulmi. Gulmi is a hill district of the Western development region of Nepal and one among the twelve districts of province five. It has been politically divided into two municipalities (Resunga and Musikot) and ten rural municipalities. The districts cover 1,149 square kilometers (444 sq. mi). The Census of 2011 identified 64,921 households with a total population of 280,160 and a female population of 159,165 in the district. The district headquarters of Gulmi is Tamghas, which is located 208 kilometers (129.8 miles) west of Kathmandu. A populationbased study using national survey data concluded that women from the hill region were more likely to report mistimed pregnancies than women from other regions, and Gulmi is also in the hill region. The data was collected from ward numbers $1,2,4,6,7,8,9,10,11,12$, and 13 wards of Resunga Municipality.

We collected data over a period of 1.5 months (October 2-November 18, $2018 \mathrm{AD}$ ) to achieve a sample size of 410 using the pretested semistructured interview schedule. We prepared a consent form and semistructured interview schedule. The questionnaire was pretested in a similar community that was different from the study site, taking $10 \%$ of the sample size to remove ambiguity in answering with the purpose of easy administration. The questionnaire was translated into Nepali and then back translated to English to ensure accuracy. The English version of the questionnaire is attached as supplementary file.

The study enquires about sociodemographic characteristics, household economic status, reproductive health and autonomy of women, which was developed based on a standard questionnaire of the Nepal Demographic Health Survey 2011 (NDHS) with some modification to the local context. The schedule was prepared in the Nepali language for the actual field study. Pregnancy intentions can be measured by using a measure of the National Survey of Family Growth (NSFG), which is also known as a conventional measure of pregnancy intentions and is most used in the United States. Recognizing the need for a more refined measure of NSFG has expanded its conventional measure, which is known as an alternative measure of pregnancy intentions. Another measure is the London Measure of unplanned pregnancy (LMUP) tool, which is validated and used in multiple settings, including South India. This LMUP tool had

Loading [MathJax]/jax/output/CommonHTML/fonts/TeX/fontdata.js Ind was used taking consent from the authority. 


\section{Data Analysis}

The collected data were edited, organized, recorded and inserted into the latest data entry program prepared by the researcher in EpiData following coding. The compiled data were exported and analyzed using the latest Statistical Package for Social Science (SPSS) software, version 25, IBM, Chicago, United States. Then, the data were analyzed using both descriptive and inferential statistics.

Data analysis was performed in three stages. In the first stage, descriptive analysis was carried out, and frequency and percentage were presented, and the mean, median and standard deviation were calculated for continuous variables as per the need. Principal component analysis was used to generate the wealth index of families using household assets.

The socioeconomic status of the surveyed families was measured using the wealth index. In determining the wealth index of the families covered in the study, the presence or absence of a list of principle elements were taken into consideration and were determined by the method commonly known as principal component analysis (factor analysis) and divided into five quintiles of wealth. The first quintile represented the poorest segment of the population, and the fifth quintile represented the least poor segment.

The second stage of analysis involved testing the association between various independent variables and pregnancy intentions. Chi-square statistics and $p$-values at the $95 \%$ level of confidence was conducted. To maintain the minimum sample size in every cell for bivariate analysis, necessary consideration was made while categorizing the response of the participants. Cross-tabulation was performed for each variable of interest with pregnancy intentions.

The third stage involved logistic regression analysis between dependent and independent variables. Both bivariate and multivariate analyses were performed to determine the existence of statistically significant associations and strength of association between the dependent and independent variables of the study. First, bivariate logistic regression was performed followed by multivariate logistic regression based on a binary logistic regression model to adjust for the effects of other variables within the model, control for possible confounders, and test the strength of any association noticed in the bivariate analysis. Those independent variables that were found to be significant in the bivariate analysis and those variables that were important but not found to be associated in this study were also included in the multivariate analysis based on previous studies. For this study, a $p$-value of 0.05 was considered significant. Hosmer and Lemeshow's goodness of fit test was carried out to ensure that the model was fit. The model was fit for our data as shown by the Hosmer and Lemeshow test, and the test statistic was $0.929(p>0.05)$.

Pregnancy intentions was the main outcome variable, which was measured using the London Measure of Unplanned Pregnancy. LMUP is a psychometrically validated measure of the degree of intentions of current and recent pregnancy that is designed to measure both pregnancy planning and intentions. It is validated in a diverse setting and is in increasing use as a research tool. LMUP includes six questions, 
score can be interpreted as $0-3$, unplanned; $4-9$, ambivalent; $10-12$, planned reflecting increasing pregnancy intention with increasing each score [25]. Independent variables were compiled in the heading of socio-demographic characteristics and reproductive health-related variables. Sociodemographic variables included maternal age, age at marriage, ethnicity, household size, education, occupation, and socioeconomic status. Reproductive health-related variables include gravida, parity, history of abortion, age of youngest child, age at first child, ideal number of children, use of contraception, spousal communication, and autonomy of woman.

\section{Ethical Considerations}

This research was approved by the Institutional Review Committee (IRC) of Institute of Medicine, Tribhuvan University (Ref: 108(6-11-E)/075/076). Formal permission was taken from the concerned authority (DPHO and Municipality) of Gulmi district. The interview was conducted only after obtaining informed verbal and written consent from the participants after explaining the study's aim, objectives, benefits, and confidentiality. In cases of illiterate participants, consent was obtained by a thumbprint on the consent form. Study participants had the right to withdraw from the study at any time. They were told that they could decline the questions if they thought were sensitive and distressing to them.

Confidentiality of each of the participants was maintained, and no personal identifier was included in the analysis. Coding and aggregate reporting were used to eliminate participants' identification and ensure anonymity. Respondents willing to know more about family planning were provided with some information at the end of the interview.

\section{Results}

A total of 410 married women who became pregnant within the last year, including current pregnancy, were enrolled in this study. The descriptions of sociodemographic and reproductive health-related variables are presented in Table 1. The scores of London Measure of Unplanned Pregnancy (LMUP) is demonstrated in Table 2. 
Table 1

Description of independent variables

\section{Variables Description}

\section{Socio-demographic characteristics}

Maternal age Completed years of age of mother during the time of data collection, categorized as $15-19$ years, $20-34$ years, and $35-49$ years

Age at Completed years of age of women when she got married, categorized as $\leq$ marriage $\quad 20$ years and $₫ 20$ years

Ethnicity Categorized as relatively advantaged, relatively disadvantaged, and disadvantaged ethnicities

Household size The number of family members of the research participant who were not separated, categorized as $1-2$ family members, $3-5$ family member, and $₫ 5$ family members

Education The educational status of a couple which was classified as illiterate, literate, basic education, secondary education and higher education

Occupation The major activities in which one engages for the maximum period, categorized as non-paid work and agriculture and non-agricultural paid work

Socio-

economic

status

SES was measured as quintiles of a wealth index derived from household assets and utilities score; the wealth quintiles were divided into five (poorest, poorer, middle, richer, richest)

\section{Reproductive health-related variables}

Gravida The total number of confirmed pregnancies that a woman has had, regardless of the outcome, categorized as Primi, Multigravida, and Grand multigravida

Parity

The number of times a female is or has been pregnant and carried the pregnancies to a viable gestational age, categorized as 1 time, 2 times, and $\geq 3$ times

History of abortion

Any history of previous miscarriage and abortion, categorized as yes and no

Age of

The total number of completed months of youngest child, categorized as $\leq 24$

youngest child months, 25-36 months, 37-48 months, 49-60 months, and $\geq 61$ months

Age at first child

Ideal number of children

Use of contraception

Spousal communication
Age in completed years at which respondent experienced first childbirth, categorized as $\leq 20$ years and $₫ 20$ years

Respondent's perception on the adequate number of children, categorized as $\leq 2$ children and $₫ 2$ children

Use of any family planning methods including modern and natural contraceptive methods by couple before the month of pregnancy, categorized as yes and no

Discussion between husband and wife regarding family planning devices, and family planning before pregnancy, categorized as yes and no 


\begin{tabular}{|ll|}
\hline Variables & Description \\
\hline $\begin{array}{l}\text { Autonomy of } \\
\text { women }\end{array}$ & $\begin{array}{l}\text { Women's involvement in the household-level decision-making process, including } \\
\text { decisions about; own health care, large household purchases, visiting family and } \\
\text { relatives and what to do with the money their husband earns, categorized as no } \\
\text { autonomy, some autonomy, and full autonomy }\end{array}$ \\
\hline
\end{tabular}


Table 2

London Measure of Unplanned Pregnancies (LMUP)

\begin{tabular}{|c|c|c|}
\hline Question & Answer & Score \\
\hline \multirow{4}{*}{$\begin{array}{l}\text { In the month that you } \\
\text { became pregnant }\end{array}$} & Not used contraception & 2 \\
\hline & Used contraception, but not on every occasion & 1 \\
\hline & $\begin{array}{l}\text { Always used contraception, but knew that the method had } \\
\text { failed (i.e., broke, moved, came off, came out, not worked, } \\
\text { etc.) at least once }\end{array}$ & 1 \\
\hline & Always used contraception & 0 \\
\hline \multirow{3}{*}{$\begin{array}{l}\text { In terms of becoming } \\
\text { a mother }\end{array}$} & Right time & 2 \\
\hline & OK time but not quite right & 1 \\
\hline & Wrong time & 0 \\
\hline \multirow{3}{*}{$\begin{array}{l}\text { Just before you became } \\
\text { pregnant }\end{array}$} & Intended to get pregnant & 2 \\
\hline & Intentions kept changing & 1 \\
\hline & Not intend to get pregnant & 0 \\
\hline \multirow{3}{*}{$\begin{array}{l}\text { Just before you became } \\
\text { pregnant }\end{array}$} & Wanted to have a baby & 2 \\
\hline & Have mixed feeling about having a baby & 1 \\
\hline & Not wanted to have a baby & 0 \\
\hline \multirow{3}{*}{$\begin{array}{l}\text { Before you became } \\
\text { pregnant, you and your } \\
\text { partner }\end{array}$} & Agreed that you both would like you to be pregnant & 2 \\
\hline & $\begin{array}{l}\text { Discussed having children together but had not agreed on you } \\
\text { to get pregnant }\end{array}$ & 1 \\
\hline & Never discussed having children together & 0 \\
\hline \multirow{2}{*}{$\begin{array}{l}\text { Health actions in } \\
\text { preparation for } \\
\text { pregnancy before falling }\end{array}$} & Took folic acid & \multirow{7}{*}{$\begin{array}{l}2=2 \\
\text { actions } \\
1=1 \\
\text { action }\end{array}$} \\
\hline & Stopped or cut down smoking & \\
\hline \multirow[t]{6}{*}{ Pregnant } & Stopped or cut down drinking alcohol & \\
\hline & Ate more healthily & \\
\hline & Sought medical /health advice & \\
\hline & Saved money before pregnancy & \\
\hline & Took some other action & \\
\hline & Did not do any of the above before your pregnancy & 0 \\
\hline
\end{tabular}




\section{Descriptive analysis}

The mean age of the respondents was 24.32 years (standard deviation $[S D]=4.302$ years), and the mean age of marriage was 18.94 ( $S D=2.689$ years). The descriptive analysis is shown in Table 3. The highest proportion of women (87.6\%) were from the age group 20-34 years of age. The youngest ( $<20$ years) respondents accounted for 10.5 percent of the total respondents. More than 77 percent of the women were married before and at the age of 20 years. Furthermore, most of the respondents were multigravida $(54.9 \% ; n=410)$, and para $2(51.3 \% ; n=232)$ aborted pregnancy at least once $(80.4 \% ; n=51)$. The mean age of the women at her first child was 20.74 ( $S D=2.714$ years). The majority (53.4\%; $n=232$ ) of the women's first childbearing age was 20 years and less, followed by 20 years above $(46.6 \% ; n=232)$. 
Table 3

Distribution of women by socio-demographic and reproductive health related characteristics

\begin{tabular}{|c|c|c|}
\hline Variables & Numbers & Percentage \\
\hline \multicolumn{3}{|l|}{ Age of women (completed years) } \\
\hline $15-19$ years & 43 & 10.5 \\
\hline $20-34$ years & 359 & 87.6 \\
\hline $35-49$ years & 8 & 2.0 \\
\hline \multicolumn{3}{|l|}{ Mean age $=24.32 \pm 4.302$} \\
\hline \multicolumn{3}{|l|}{ Age at marriage (completed years) } \\
\hline$\leq 20$ years & 317 & 77.3 \\
\hline$\otimes 20$ years & 93 & 22.7 \\
\hline \multicolumn{3}{|l|}{ Mean age $=18.94 \pm 2.689$} \\
\hline \multicolumn{3}{|l|}{ Ethnicity } \\
\hline Relatively advantage & 210 & 51.2 \\
\hline Relatively disadvantage & 97 & 23.7 \\
\hline Disadvantage & 103 & 25.1 \\
\hline \multicolumn{3}{|l|}{ Family size (numbers) } \\
\hline 1-2 family members & 5 & 1.2 \\
\hline 3-5 family members & 191 & 46.6 \\
\hline$₫ 5$ family members & 214 & 52.2 \\
\hline \multicolumn{3}{|l|}{ Mean number $=6.31 \pm 2.902$} \\
\hline \multicolumn{3}{|l|}{ Women's educational status } \\
\hline Illiterate & 4 & 1.0 \\
\hline Literate & 17 & 4.1 \\
\hline Basic education & 82 & 20.0 \\
\hline Secondary education & 217 & 52.9 \\
\hline Higher education & 90 & 22.0 \\
\hline \multicolumn{3}{|l|}{ Husbands' educational status } \\
\hline Illiterate & 1 & 0.2 \\
\hline Loading [MathJax]/jax/output/CommonHTML/fonts/TeX/fontdata.js & 11 & 2.7 \\
\hline
\end{tabular}




\begin{tabular}{|c|c|c|}
\hline Variables & Numbers & Percentage \\
\hline Basic education & 77 & 18.8 \\
\hline Secondary education & 225 & 54.9 \\
\hline Higher education & 96 & 23.4 \\
\hline \multicolumn{3}{|l|}{ Women's occupation } \\
\hline Nonpaid work and agriculture & 343 & 83.7 \\
\hline Non-agricultural paid work & 67 & 16.3 \\
\hline \multicolumn{3}{|l|}{ Husbands' occupation } \\
\hline Nonpaid work and agriculture & 31 & 7.6 \\
\hline Non-agricultural paid work & 379 & 92.4 \\
\hline \multicolumn{3}{|l|}{ Number of pregnancies $(n=410)$} \\
\hline Primi & 175 & 42.7 \\
\hline Multigravida & 225 & 54.9 \\
\hline Grand multigravida & 10 & 2.4 \\
\hline \multicolumn{3}{|l|}{ Parity $(n=232)$} \\
\hline 1 & 83 & 35.8 \\
\hline 2 & 119 & 51.3 \\
\hline$\geq 3$ & 30 & 12.9 \\
\hline \multicolumn{3}{|l|}{ Abortion $(n=235)$} \\
\hline Yes & 51 & 21.7 \\
\hline No & 184 & 78.3 \\
\hline \multicolumn{3}{|l|}{ Frequency of abortions $(n=51)$} \\
\hline 1 & 41 & 80.4 \\
\hline$\geq 2$ & 10 & 19.6 \\
\hline \multicolumn{3}{|l|}{ Main reason for abortion $(n=51)$} \\
\hline Spontaneous & 31 & 60.8 \\
\hline Sex selective & 8 & 15.7 \\
\hline Young child & 3 & 5.9 \\
\hline $\begin{array}{l}\text { nthnre } \\
\text { Loading [MathJax]/jax/output/Co }\end{array}$ & 9 & 17.6 \\
\hline
\end{tabular}




\begin{tabular}{|c|c|c|}
\hline Variables & Numbers & Percentage \\
\hline \multicolumn{3}{|c|}{ Age of young child (completed months) $(n=232)$} \\
\hline$\leq 24$ months & 142 & 61.2 \\
\hline $25-36$ months & 17 & 7.3 \\
\hline 37-48 months & 17 & 7.3 \\
\hline $49-60$ months & 22 & 9.5 \\
\hline$\geq 61$ months & 34 & 14.7 \\
\hline \multicolumn{3}{|c|}{ Median month $=11.00(\mathrm{Q} 1=4.00, \mathrm{Q} 3=48.00)$} \\
\hline \multicolumn{3}{|c|}{$\begin{array}{l}\text { Age of women at her first child (completed years) }(n= \\
232)\end{array}$} \\
\hline$\leq 20$ years & 124 & 53.4 \\
\hline$₫ 20$ years & 108 & 46.6 \\
\hline \multicolumn{3}{|c|}{ Mean age $=20.74 \pm 2.714$} \\
\hline \multicolumn{3}{|c|}{ Ideal number of children $(n=410)$} \\
\hline$\leq 2$ & 388 & 94.6 \\
\hline$\unrhd 2$ & 22 & 5.4 \\
\hline \multicolumn{3}{|c|}{ Spousal communication $(n=410)$} \\
\hline Yes & 360 & 87.8 \\
\hline No & 50 & 12.2 \\
\hline \multicolumn{3}{|c|}{ Decision on FP $(n=410)$} \\
\hline Self & 63 & 15.4 \\
\hline Husband & 87 & 21.2 \\
\hline Both & 260 & 63.4 \\
\hline \multicolumn{3}{|c|}{ Husbands' opposition in FP use $(n=410)$} \\
\hline Yes & 131 & 32.0 \\
\hline No & 279 & 68.0 \\
\hline \multicolumn{3}{|c|}{ FP use before pregnancy $(n=410)$} \\
\hline Yes & 127 & 31.0 \\
\hline No & 283 & 69.0 \\
\hline
\end{tabular}




\begin{tabular}{|c|c|c|c|}
\hline \multicolumn{2}{|l|}{ Variables } & Numbers & Percentage \\
\hline \multicolumn{4}{|c|}{ Methods of FP use before pregnancy $(n=127)$} \\
\hline \multicolumn{2}{|l|}{ Modern } & 94 & 74.0 \\
\hline \multicolumn{2}{|l|}{ Natural } & 33 & 26.0 \\
\hline \multicolumn{4}{|c|}{ Future intention of using FP $(n=410)$} \\
\hline \multicolumn{2}{|l|}{ Intended } & 109 & 26.6 \\
\hline \multicolumn{2}{|l|}{ Unintended } & 301 & 73.4 \\
\hline \multicolumn{4}{|c|}{ Pregnancy intentions $(n=410)$} \\
\hline \multicolumn{2}{|l|}{ Intended } & 162 & 39.5 \\
\hline \multirow[t]{3}{*}{ Unintended } & Unplanned & 78 & 19.0 \\
\hline & Ambivalent & 170 & 41.5 \\
\hline & Total & $\begin{array}{l}(\mathrm{Cl}=55.769-65.231) \\
248\end{array}$ & 60.5 \\
\hline \multicolumn{4}{|c|}{ Level of autonomy $(n=410)$} \\
\hline \multicolumn{2}{|l|}{ No autonomy } & 291 & 71.0 \\
\hline \multicolumn{2}{|l|}{ Some autonomy } & 106 & 25.9 \\
\hline \multicolumn{2}{|l|}{ Full autonomy } & 13 & 3.2 \\
\hline
\end{tabular}

The study revealed that the majority $(94.6 \% ; n=410)$ of the women had two and fewer children as an ideal number of children, and the remaining $(5.4 \% ; n=410)$ expressed more than two children as the preferred number of children. It was interesting to see that approximately 32.0 percent $(n=410)$ of the women's husbands oppose family planning use. According to this study, 12.2 percent $(n=410)$ of the women never discussed family planning with their husbands before using contraception. Approximately 31.0 percent $(n=410)$ of the respondents reported that they were using any kind of contraceptive method to prevent pregnancy, with the majority of modern methods users $(74.0 \% ; n=127)$. One in four women adopted natural methods $(26.0 \% ; n=127)$ for the prevention of pregnancy before the current pregnancy. In addition, $71.0 \%(n=410)$ of women reported having no autonomy followed by some autonomy $(25.9 \%$; $n=410)$ and full autonomy $(3.2 \% ; n=410)$.

The data showed that out of 410 pregnancies, $248(60.5 \% ; n=410)$ pregnancies were unintended, of which 78 (19.0\%) were unplanned and 170 (41.5\%) were ambivalent. The remaining $162(39.5 \% ; n=410)$ pregnancies were considered intended. 


\section{Bivariate analysis}

The bivariate analysis is shown in Table 4. The chi-square analysis showed that female age, socioeconomic status, husband opposition, methods used before pregnancy, and intention to use contraception in the future were significantly associated with pregnancy intentions. The analysis showed that marriage age, ethnicity, family size, women's education, spousal education, women's occupation, spousal occupation, and other reproductive health-related characteristics and level of autonomy were not significantly associated with the pregnancy intention of women of reproductive age group despite the fact that their significance has been reported in other studies. 
Table 4

Association of pregnancy intentions with socio-demographic and reproductive health related variables Variable Pregnancy intentions

Unintended $\mathbf{n}$

(\%)

$\begin{array}{ll}\text { Intended } & \begin{array}{l}\text { Chi-square } \\ \text { value }\end{array} \\ \mathrm{n}(\%) & \end{array}$

p-value

$n(\%)$

\section{Age of women}

$\begin{array}{lllll}\leq 19 & 34(79.1) & 9(20.9) & 6.940 & 0.008^{*} \\ \geq 20 & 214(58.3) & 153 & & \\ & & (41.7) & \end{array}$

\section{Marriage age of women}

$\leq 20$ years

$197(62.1)$

120

(37.9)

$₫ 20$ years

$51(54.8)$

$42(45.2)$

\section{Ethnicity}

Relatively advantage

119 (56.7)

$91(43.3)$

2.646

0.266

Relatively disadvantage

$63(64.9)$

$34(35.1)$

Disadvantage

$66(64.1)$

37 (35.9)

\section{Family members}

$\leq 6$

$154(61.6)$

96 (38.4)

0.332

0.565

$\bowtie 6$

$94(58.8)$

$66(41.3)$

\section{Women education}

Illiterate and non-formal education

Formal education

$14(66.7)$

7 (33.3)

0.354

0.552

$234(60.2)$

155

\section{Husband education}

Illiterate and non-formal education

$4(33.3)$

$8(66.7)$

2.733

0.098

Formal education

$244(61.3)$

154

(38.7)

\section{Women occupation}

Nonpaid work and agriculture

$207(60.3)$

136

0.017

0.897

(39.7)

Non-aaricultural paid work

41 (61.2)

$26(38.8)$

Loading [MathJax]/jax/output/CommonHTML/fonts/TeX/fontdata.js 


\section{Variable}

\section{Husband occupation}

Nonpaid work and agriculture

Non-agricultural paid work

Wealth quintiles

First quintile

Second quintile

Third quintile

Fourth quintile

Fifth quintile

Gravida $(n=410)$

Primi

Multigravida

Parity $(n=232)$

$\leq 2$ para

$\bigotimes 2$ para

Abortion $(n=235)$

Yes

No

Abortion times $(n=51)$

One time

$\geq 2$

Main cause of abortion $(n=51)$

Spontaneous

Non-spontaneous

Age of young child $(n=232)$

$\leq 12$ months

73 (56.6)

63 (61.2)

Loading [MathJax]/jax/output/CommonHTML/fonts/TeX/fontdata.js

\section{Pregnancy intentions}

$23(74.2)$

$8(25.8) \quad 2.636$

0.104

$225(59.4)$

154

$(40.6)$
$61(74.4)$

$43(58.9)$

$37(43.5)$

$52(59.1)$

$55(67.1)$

$110(62.9)$

$138(58.7)$

$114(56.4)$

$22(73.3)$

$31(60.8)$

107 (58.2)

$25(61.0)$

$6(60.0)$

18 (58.1)

$13(65.0)$
20 (39.2)

0.114

0.735

77 (41.8)

3.075

0.080

8 (26.7)

16 (39.0) $\quad 0.000$

1.000

$4(40.0)$

$13(41.9) \quad 0.245$

0.620

7 (35.0)

$56(43.4) \quad 0.494$

0.482 


\section{Variable}

Age of mother at her first child $(n=232)$

$\leq 20$ years

$₫ 20$ years

Ideal number of children $(n=410)$

$\leq 2$

$\nabla 2$

\section{Spousal communication}

Yes

No

\section{Decision on FP use}

\section{Self}

Husband

Both

Husband opposition in FP use

Yes

No

FP use before pregnancy $(n=410)$

Yes

68 (53.5)

$180(63.6)$
$235(60.6)$

$13(59.1)$
$75(60.5)$

(5)
$29(58.0)$

$42(66.7)$

$59(67.8)$

$147(56.5)$

91 (69.5)

157 (56.3)

No
49 (39.5) $\quad 0.381$

47 (43.5)
153

(39.4)

$9(40.9)$

0.019

0.890

Pregnancy intentions

141

(39.2)

$21(42.0)$

0.147

0.701

21 (33.3)

4.658

0.097

28 (32.2)

113

(43.5)

40 (30.5)

6.492

$0.011^{*}$

122

(43.7)

$59(46.5)$

3.713

0.054

103

(36.4)

FP method use before pregnancy $(n=$ 127)

Natural

Modern

Future intention to use FP $(n=410)$

Not intended

Loading [MathJax]/jax/output/CommonHTML/fonts/TeX/fontdata.js
$10(30.3)$

$58(61.7)$

$171(56.8)$

130

$(43.2)$
$23(69.7) \quad 9.681$

$0.002^{*}$

$36(38.3)$

Page 20/35 


\begin{tabular}{|c|c|c|c|c|}
\hline \multirow{2}{*}{$\begin{array}{l}\text { Variable } \\
\text { Intended }\end{array}$} & \multicolumn{4}{|c|}{ Pregnancy intentions } \\
\hline & $77(70.6)$ & $32(29$ & & \\
\hline \multicolumn{5}{|l|}{ Level of autonomy } \\
\hline No autonomy & $166(57.0)$ & $\begin{array}{l}125 \\
(43.0)\end{array}$ & 5.305 & 0.070 \\
\hline Some autonomy & $74(69.8)$ & $32(30$ & & \\
\hline Full autonomy & $8(61.5)$ & $5(38$. & & \\
\hline
\end{tabular}

The proportion of unintended pregnancies was highest among women younger than 20 years $(79.1 \%)$ compared to women aged 20 and older (58.3\%). However, intended pregnancy was highest among women aged 20 years and older (41.7\%). These differences in pregnancy intentions by age group were statistically significant with a $p$-value of 0.008 in the chi-square analysis. However, the association became statistically nonsignificant when adjusted for other variables in multivariate analysis. The proportion of unintended pregnancies was highest among the women who were married before 20 years $(62.1 \%)$ of age compared to women who were married after 20 years $(54.8 \%)$. In contrast, the proportion of intended pregnancies was highest among women who were married after 20 years of age $(45.2 \%)$. Most of the unintended pregnancies were from a relatively disadvantaged (64.9\%) ethnic group, followed by a disadvantaged (64.1\%) and relatively advantageous (56.7\%) ethnic group. Most of the unintended pregnancies were among women who belonged to the first wealth quintile $(74.4 \%)$, and intended pregnancies were more common among women who belonged to the third wealth quintile $(56.5 \%)$. It is also statistically significant in chi-square analysis with $p$-value 0.001 .

Unintended pregnancies were high among women who were Primi (62.9\%), had more than two para (73.3\%), had done abortion (60.8\%), and had done an abortion at least one time (61.0\%) nonspontaneously (65.0\%). More than 60 percent of unintended pregnancies were among women whose youngest child was more than one year and who delivered her first child before or at 20 years of age $(60.5 \%)$. Most of the unintended pregnancies were among women who preferred less than or equal to 2 children $(60.6 \%)$ as an ideal number of the child. Approximately 58.0 percent of unintended pregnancies were among women who did not discuss with her husband before using contraception. There were 69.5 percent of unintended pregnancies among women whose husbands opposed using contraception. Other factors significantly associated with pregnancy intentions, as shown by bivariate analysis, were husband opposition in using contraception $(p=0.011)$, method of family planning used before pregnancy $(p=$ $0.002)$ and women's intention to use contraception in the future $(p=0.011)$.

\section{Multivariate binary logistic regression}


The multivariate binary logistic regression is shown in Table 5. In the multivariate logistic regression model, after possible effects of confounders were adjusted, the method of family planning used before pregnancy and wealth quintiles as the independent variable were significantly associated with pregnancy intentions at $95 \% \mathrm{Cl}$. Women from the second $(A O R=0.048, \mathrm{Cl}=0.007-0.329)$ and third $(A O R=0.134, \mathrm{Cl}$ $=0.026-0.702)$ wealth quintiles had a lower chance of having an unintended pregnancy in comparison to women from the fifth wealth quintile. Women who used the natural family planning method before pregnancy had a lower chance of having an unintended pregnancy than women who used the modern family planning method before pregnancy $(A O R=0.078, C l: 0.016-0.390)$. However, husband opposition to use contraception, parity, the ideal number of children, spousal communication, level of autonomy, and future intention of using contraception were not depicted to be associated with pregnancy intentions as per this study. 
Table 5

Multivariate logistic regression analysis for possible predictors of unintended pregnancy

\begin{tabular}{|c|c|c|c|}
\hline Variable & Crude Odds Ratio $95 \% \mathrm{Cl}$ & Adjusted Odds Ratio 95\% Cl & $p$-value \\
\hline \multicolumn{4}{|c|}{ Wealth quintiles $(n=410)$} \\
\hline First quintile & $1.426(0.725-2.806$ & $0.698(0.075-6.484)$ & 0.751 \\
\hline Second quintile & $0.704(0.365-1.355)$ & $0.048(0.007-0.329)$ & $0.002^{*}$ \\
\hline Third quintile & $0.378(0.202-0.710)$ & $0.134(0.026-0.702)$ & $0.017 *$ \\
\hline Fourth quintile & $0.709(0.379-1.327)$ & $0.334(0.072-1.546)$ & 0.161 \\
\hline Fifth quintile & Ref. & & \\
\hline \multicolumn{4}{|c|}{ Husband opposition to use FP $(n=410)$} \\
\hline Yes & $1.768(1.138-2.747)$ & $2.085(0.670-6.493)$ & 0.205 \\
\hline No & Ref. & & \\
\hline \multicolumn{4}{|c|}{ Method of FP use before pregnancy $(n=127)$} \\
\hline Natural & $0.270(0.115-0.632)$ & $0.078(0.016-0.390)$ & $0.002^{*}$ \\
\hline Modern & Ref. & & \\
\hline \multicolumn{4}{|c|}{ Future intention of using FP $(n=410)$} \\
\hline Not intended & $0.547(0.341-0.876)$ & $0.373(0.055-2.534)$ & 0.313 \\
\hline Intended & Ref. & & \\
\hline \multicolumn{4}{|c|}{ Ideal number of children $(n=410)$} \\
\hline$\leq 2$ & $1.063(0.444-2.548)$ & $0.568(0.087-3.717)$ & 0.555 \\
\hline$\otimes 2$ & Ref. & & \\
\hline \multicolumn{4}{|c|}{ Spousal communication $(n=410)$} \\
\hline No & $0.889(0.488-1.620)$ & $0.975(0.131-7.280)$ & 0.980 \\
\hline Yes & Ref. & & \\
\hline \multicolumn{4}{|l|}{ Parity $(n=232)$} \\
\hline$\leq 2$ para & $0.471(0.200-1.108)$ & $0.204(0.033-1.244)$ & 0.085 \\
\hline$₫ 2$ para & Ref. & & \\
\hline \multicolumn{4}{|c|}{ Level of autonomy $(n=410)$} \\
\hline No autonomy & $0.830(0.265-2.598)$ & $0.142(0.005-3.800)$ & 0.245 \\
\hline MathJax]/jax/outpu & רonHTML/fonts/Te & $0.200(0.007-5.570)$ & 0.343 \\
\hline
\end{tabular}




\begin{tabular}{|c|c|c|c|}
\hline Variable & Crude Odds Ratio $95 \% \mathrm{Cl}$ & Adjusted Odds Ratio 95\% Cl & $p$-value \\
\hline Full autonomy & Ref. & & \\
\hline
\end{tabular}

The analysis was fit in a logistic regression model:

$y=\beta_{0}+\beta_{1} X_{1}+\beta_{2} X_{2}+\beta_{3} X_{3} \ldots \ldots \ldots . .+\beta_{i} X_{i}$

where $y$ is the log odds of the dependent variable, $\beta_{0}$ is a constant, $\beta_{i}$ is the regression coefficient and $X i$ is an independent variable. The logistic regression revealed the following equation for pregnancy intentions:

Pregnancy intentions $(y)=6.485+(-3.029) X_{1}+(-2.012) X_{2}+(-2.550) X_{3}$

where,

Constant $\left(\beta_{0}\right)=6.485$

Beta coefficient $\left(\beta_{7}\right)=-3.029, X_{1}=$ Second wealth quintile

Beta coefficient $\left(\beta_{2}\right)=-2.012, X_{2}=$ Third wealth quintile

Beta coefficient $\left(\beta_{3}\right)=-2.550, X_{3}=$ Use of natural family planning method

The equation for the regression line can be depicted as follows:

Pregnancy intentions $=$ Constant $(6.485)+(-3.029)$ Second wealth quintile $+(-2.012)$ Third wealth quintile $+(-2.550)$ Use of natural family planning method

\section{Discussion}

The findings of the study showed that $248(60.5 \%)$ pregnancies were unintended pregnancies, of which 78 (19.0) were unplanned and 170 (41.5\%) were ambivalent in total. The remaining 162 (39.5\%) pregnancies were considered intended. This finding is consistent with the estimated national prevalence of unintended pregnancy by NDHS 2016 [24]. A hospital-based cross-sectional survey conducted in Pakistan in 2015 adopting the LMUP tool revealed 38.3\% unintended pregnancies, of which 13.9 percent were ambivalent and 24.3 percent were unplanned [26]. Similarly, a study carried out on the basis of the NDHS 2011 dataset in 2015 showed that the unintended pregnancy rate was 24.59\% [6]. In 2012, 40 percent of pregnancies were unintended globally [9]. A community-based cross-sectional study carried out in Ethiopia in 2013 showed 36.5 percent unintended pregnancy [13]. The estimate of this study is higher than that of previously reported data, which might be because previous studies used a dichotomous scale, whereas this study employed six-item LMUP. The prevalence of unintended 
pregnancy in this study is higher than that of the studies from Ethiopia (36.5\%) [13], Pakistan (38.3\%) [17], Bangladesh (40\%) [27] and Brazil (55.4\%) [14].

In our study, age was significantly associated with unintended pregnancy. Young women below the age of 20 years were more likely to report unintended pregnancy in comparison to women from the above age group, with a similar pattern from other studies of Nepal [6], Ethiopia [28], Pakistan [17], Malawi [21], Nairobi, Kenya [29], and Congo [27]. These effects of age on unintended pregnancy can be explained by the fact that young women may have sexual relations for reasons other than childbearing, and they may have inadequate knowledge and skills regarding birth control, therefore increasing the likelihood of pregnancies being unintended [30].

Likewise, the number of family members was not found to be associated with unintended pregnancy in this study, which is consistent with the findings of Ethiopia [28]. This study revealed a higher percentage of unintended pregnancies among women with less than or equal to six family members than among women with more than six family members. The reason might be that women with a small number of family members may perceive their pregnancy as unintended due to the lack of care takers in house and being unable to allocate time for rearing and caring of children.

Regarding the educational status of respondents' husbands, it has been found that couples with higher education have better knowledge of the uses and benefits of family planning, making every pregnancy planned. In contrast, it was found not to be associated with pregnancy intentions. This is consistent with the findings made from another study conducted in Nepal [6] but contrasts with the findings of a study by Malawi [21] and Congo [27], where there was an association between partner's education and pregnancy intention. This study has shown a higher percentage of unintended pregnancies among women whose husbands had taken formal education. The reason might be simply because they might have more confidence regarding the ability to control the timing of their pregnancies [6] and could also be because of negligence.

In the current study, the occupation of women was not found to be associated with unintended pregnancy, which is similar to the finding of a study in Egypt [31]. However, this finding is contrasting with the findings of a study of Nepal [6], Iran [32], and Brazil [14], which could be because of differences in circumstances and varying natures in the measurement of study variables. This study has resulted higher percentage of unintended pregnancies among women who were engaged in non-agricultural paid work. This could be due to being more career oriented and due to lack of leave as per their requirements, making them perceive their pregnancy unintended.

A significant association was seen between pregnancy intentions and socioeconomic status after adjusting for other factors, which is similar to the findings of Ethiopia [28] and Nigeria [33]. This finding contradicts the findings made in Nepal [6] and Pakistan [17]. Women from the lower wealth quintile that means the low-income group (the second $(A O R=0.048, C l=0.007-0.329)$ and third $(A O R=0.134, C l=$ $0.026-0.702$ ) wealth quintiles) had a lower chance of having an unintended pregnancy in comparison to Loading [MathJax]/jax/output/CommonHTML/fonts/TeX/fontdata.js uld be because this study has not included 
educational status in the construction of the wealth index [28]. Therefore, education may play a vital role in decision making.

Gravidity was not found to be associated with pregnancy intention in this study, which is similar to the finding of a study by Ethiopia [34], but it contradicts the finding of a study by Tanzania [30] and Canada [35], where there was a significant association between the number of pregnancies and unintended pregnancies. In this study, there was a higher percentage of unintended pregnancies among women who had been pregnant for the first time. The reason behind this finding might be that first pregnancy might not necessarily be planned, making that unintended.

The frequency of abortion was not found to be associated with unintended pregnancy in this study, which is consistent with the findings of a study in Egypt [31]. This study revealed a higher percentage of unintended pregnancies among women who had terminated their pregnancies at least once compared to those who had terminated their pregnancies more than or equal to twice. This result might be because women who had terminated their pregnancy more than once may become more cautious toward pregnancy planning due to the experience of complications and consequences of abortion.

The age of the youngest child was not found to be statistically significant with pregnancy intentions in this study, which contradicts the findings of a study of Malawi in which time since last birth was associated with pregnancy intentions [21]. There was a lower percentage of unintended pregnancies among women whose young child was less than and equal to twelve months of age. This could be because couples might feel comfortable raising both children with a short gap between them so that they grow together.

Communication between husbands and wives regarding contraception might help to involve husbands in contraception decisions, leading to increased acceptance of contraception utilization and decreased failures. In contrast to this concept, it was not found to be associated with pregnancy intentions in this study, which is similar to the findings of Congo [27] and Ethiopia [34]. This finding is inconsistent with the findings of Tanzania [30], Ethiopia [19], and Egypt [31]. In this study, there was a 2.8 percent higher prevalence of unintended pregnancy among women who had communication with their husband. The reason might be that although they have communication between partners, women might not have autonomy to decide on fertility [34].

Husbands play a major role in family planning utilization. Husband opposition in using contraception was found to be significantly associated with pregnancy intention in the bivariate analysis of this study. This finding is inconsistent with the results of the study of Ethiopia [36]. There were 69.5 percent of unintended pregnancies among women whose husband opposed using contraception, which is higher than that of Ethiopia, where there was 18.5 percent unintended pregnancy due to husband refusal to use contraception [37]. The reason might be due to the lack of autonomy regarding household decision making and deciding their health needs, including lack of knowledge regarding consequences of unintended pregnancy [36]. 
A significant association was seen between pregnancy intentions and method of family planning used before pregnancy to control pregnancy in bivariate and multivariate analyses in this study. This finding is similar to the outcome of a study by Congo [27] and Bangladesh [38]. Similarly, behind the higher probability of unintended pregnancy among women who had used modern contraception before pregnancy, there might be a possibility of problems with contraceptive use effectiveness, including contraceptive discontinuation and failure [38]. Another view might be that the users of modern methods might have high expectations towards limiting and spacing their pregnancies and misconceptions regarding lower fertility while using contraception. Therefore, they may consider their pregnancy as unintended [39].

The intention of women to use contraception in the future was found to be significantly associated with pregnancy intentions in the bivariate analysis in this study. There was a lower risk of having unintended pregnancy among women who had not intended to use contraception in the future $(O R=0.547, \mathrm{Cl}=$ $0.341-0.876$ ) in comparison to those who intended to use contraception in the future. This finding is inconsistent with the outcome of the study of Nepal [6], where there were lower odds of unwanted pregnancy among women who were intended to use contraception in the future. The reason behind this finding might be that this study assessed intention to use contraception in the future as a proxy measure of behavior. The possible gap between intention and actual practice of women could be the presence of some factors that were considered to be constraints to their intentions to use contraception in the future, such as husbands' opposition and fear side effects. making differences between intentions and actual behavior [31].

Empowered women with strong decision-making power in major household decision making are more likely to plan their pregnancy. However, in contrast to previous literature, the level of autonomy was not found to be associated with pregnancy intentions in this study, which is similar to the finding of a study of Nepal that was conducted in 2009 [16] and contradicts the finding made from a study based on the NDHS dataset of 2011 in Nepal [6], Ethiopia [19], India [18], and Bangladesh. The study of Bangladesh has shown that a one-unit increase in the autonomy scale decreases the odds of unintended pregnancy by $16 \%$ [40]. In this study, most unintended pregnancies were among women with some autonomy. The mechanism behind this might be due to taking previous or current pregnancy unintended because of lower fertility aspiration by empowered women or limited decision-making opportunities to women being in the patriarchal society $[6,16]$.

Although this study was strengthened by being community-based research and having used the validated pregnancy intentions scale (LMUP tool) to measure the pregnancy intentions of women, it had some notable limitations. This was a cross-sectional study, so it does not allow causal inference for pregnancy intentions and other independent variables, such as sociodemographic and reproductive health-related variables. This study included only married women, whereas the majority of unintended pregnancies resulted from illegitimate sexual intercourse, which is more common among sexually active teenagers and unmarried women. In addition, another limitation might be social desirability bias, leading to 
unintended pregnancies. Similarly, this study does not determine the intentions and associated factors of women who terminate their pregnancy by abortion and miscarriage. Lastly, the results may not be generalized to the whole country, as the study was conducted in one municipality of a district.

\section{Conclusion}

This study estimated the prevalence of unintended and intended pregnancy among married women of reproductive age and identified the factors associated with it. The study showed that unintended pregnancy is still high, and more than fifty percent of pregnancies are unintended. The factors that were found to be associated with an unintended pregnancy were socioeconomic status and method of family planning used before pregnancy. Women who were from the second and third wealth quintiles were less likely to have an unintended pregnancy than those from the fifth wealth quintile. Likewise, women who used the natural family planning method before the most recent pregnancy were less likely to experience an unintended pregnancy than those who used a modern method of contraception before pregnancy. Therefore, the relationship between the use of modern methods and increased risk of unintended pregnancy suggests an urgent need for further research.

However, other study factors, such as marriage age of women, ethnicity, family members, women's education, husbands' education, women's occupation, husbands' occupation, gravidity, parity, history, frequency, reason of abortion, age of youngest child, age of women at her first child, ideal number of children, and contraception use before pregnancy, were not found to be associated with pregnancy intentions. Spousal communication and autonomy of women were also not associated with pregnancy intentions.

Unintended pregnancy was high in this study, so awareness programs should be raised at the community level. Women using natural family planning methods before pregnancy are less likely to have an unintended pregnancy. The use of natural family planning methods is not always accurate. Therefore, both types of methods need to be equally valued and promoted. Efforts to increase the knowledge and availability of family planning, especially the different methods, should be strengthened. The use of modern methods and increased risk of unintended pregnancy suggests an urgent need for further research. A qualitative study is recommended to explore the relationship between unintended pregnancy and the method of contraception used before pregnancy and socioeconomic status of the family. At the same time, it is a cross-sectional study that might not have shown a causal relation between various independent variables and pregnancy intentions. Therefore, further studies are required to evaluate the causal relationship between independent variables and pregnancy intentions.

\section{Abbreviations}




\begin{tabular}{|ll|}
\hline ANC & Antenatal Care \\
\hline BDHS & Bangladesh Demographic and Health Survey \\
\hline CAC & Comprehensive Abortion Care \\
\hline CREHPA & Center for Research on Environment Health and Population Activities \\
\hline DHS & Demographic and Health Survey \\
\hline DPHO & District Public Health Office \\
\hline FCHV & Female Community Health Volunteer \\
\hline FP & Family Planning \\
\hline FPAN & Family Planning Association of Nepal \\
\hline GA & Gestational Age \\
\hline IRC & Institutional Review Committee \\
\hline LMUP & London Measure of Unplanned Pregnancy \\
\hline MPH & Master of Public Health \\
\hline NDHS & National Demographic and Health Survey \\
\hline NGO & Non-governmental Organization \\
\hline NHRC & Nepal Health Research Council \\
\hline NSFG & National Survey of Family Growth \\
\hline SPSS & Statistical Package for Social Sciences \\
\hline
\end{tabular}

\section{Declarations}

\section{Ethical Approval and Consent to Participate}

This research was approved by the Institutional Review Committee (IRC) of Institute of Medicine, Tribhuvan University (Ref: 108(6-11-E)/075/076). The interview was conducted only after obtaining informed verbal and written consent signature from the participants. In case of illiterate participants, the consent to participate was obtained by a thumbprint. The written consent to participate was obtained from the parent or the guardian for participants under 16 years of age.

\section{Consent for Publication}

Not Applicable. 


\section{Availability of data and materials}

The study data materials will be provided upon request to the corresponding author. The questionnaire used in this study was self-developed and has not previously been published elsewhere. The questionnaire has been attached as a supplementary file along with this manuscript.

\section{Competing Interests}

The authors declare that they have no competing interests.

\section{Funding}

Not applicable

\section{Authors' Contributions}

RK has contributions in research conceptualization, research design, data collection, statistical analysis, results interpretation, and wrote the initial draft and the final version of the manuscript.

GK has contributed in manuscript design.

SM has contributed in manuscript design, final version manuscript writing and performed statistical analysis of the study.

JS has contributed in data collection.

All authors read and approved the final manuscript.

\section{Acknowledgements}

This research paper is the master thesis in public health by Rita Karki. I am very indebted to the substantial support and encouragement of my professors, my friends and my family. I am deeply indebted to my thesis supervisor, Associate Prof. Dr. Amod Kumar Poudyal and co-supervisor Assistant professor Anil K. Singh, for their guidance, supervision, and encouragement throughout the process of my thesis.

\section{References}

1. Government of Nepal NPCS. National Population and Housing Census 2011 (National Report). In: National Plannina Commission Secretariat. Nebal. Kathmandu; 2012. p. 1-278. 
2. Puri, Singh, Sundaram, Hussain, Tamang, Crowell. Abortion Incidence and Unintended Pregnancy in Nepal. Int Perspect Sex Reprod Health. 2016;42:197.

3. Bhadari T, Dangal G. Maternal Mortality: Paradigm Shift in Nepal. Nepal J Obstet Gynaecol. 2014;7:3-8.

4. Santelli JS, Lindberg LD, Orr MG, Finer LB, Speizer I. Toward a multidimensional measure of pregnancy intentions: Evidence from the United States. Studies in Family Planning. 2009;40:87-100.

5. Kost K, Lindberg L. Pregnancy Intentions, Maternal Behaviors, and Infant Health: Investigating Relationships With New Measures and Propensity Score Analysis. Demography. 2015;52:83-111.

6. Acharya P, Gautam R, Aro AR. FACTORS INFLUENCING MISTIMED AND UNWANTED PREGNANCIES AMONG NEPALI WOMEN. J Biosoc Sci. 2016;48:249-66.

7. Public Health Division LHS. Prams and Unintended Pregnancy. 2010.

8. Guttmacher institute. Unintended pregnancy in the United States. 125 Maiden Lane New York, NY $10038212.248 .1111 ; 2016$.

9. Sedgh G, Singh S, Hussain R. Intended and Unintended Pregnancies Worldwide in 2012 and Recent Trends. Stud Fam Plann. 2014;45:301-14.

10. Singh S, Sedgh G, Hussain R. Unintended Pregnancy: Worldwide Levels, Trends, and Outcomes. Stud Fam Plann. 2010;41:241-50.

11. Yazdkhasti M, Pourreza A, Pirak A, Abdi F. Unintended pregnancy and its adverse social and economic consequences on health system: A narrative review article. Iran J Public Health. 2015;44:12-21.

12. United States Department of Health and Human Services HR and SA. Child Health USA 2013. Rockville, Maryland; 2013.

13. Teshome FT, Gebremariam Hailu A, Nigussie Teklehaymanot A. Associated Factors among Married Pregnant Women in Ganji Woreda. Sci J Public Heal. 2014;2:92-101.

14. Theme-Filha MM, Baldisserotto ML, Fraga ACSA, Ayers S, da Gama SGN, Leal M do C. Factors associated with unintended pregnancy in Brazil: cross-sectional results from the Birth in Brazil National Survey, 2011/2012. Reprod Health. 2016;13:118.

15. Bishwajit G, Tang S, Yaya S, Feng Z. Unmet need for contraception and its association with unintended pregnancy in Bangladesh. BMC Pregnancy Childbirth. 2017;17:1-9.

16. Adhikari R, Soonthorndhada K, Prasartkul P. Correlates of unintended pregnancy among currently pregnant married women in Nepal. BMC Int Health Hum Rights. 2009;9:17.

17. Habib MA, Raynes-Greenow C, Nausheen S, Soofi SB, Sajid M, Bhutta ZA, et al. Prevalence and determinants of unintended pregnancies amongst women attending antenatal clinics in Pakistan. BMC Pregnancy Childbirth. 2017;17:1-10.

18. Dutta M, Shekhar C, Prashad L. Level, trend and correlates of mistimed and unwanted pregnancies among currently pregnant ever married women in India. PLoS One. 2015;10:1-11. 
19. Geda NR, Lako TK. Unintended pregnancy among married women in Damot Gale District, Southern Ethiopia: Examining the prevalence and risk factors. Etude la Popul Africaine. 2012;26:96-112.

20. Habte D, Teklu S, Melese T, Magafu MGMD. Correlates of Unintended Pregnancy in Ethiopia: Results From a National Survey. PLoS One. 2013;8:e82987.

21. Hall JA, Barrett G, Phiri T, Copas A, Malata A, Stephenson J. Prevalence and determinants of unintended pregnancy in Mchinji district, Malawi; using a conceptual hierarchy to inform analysis. PLoS One. 2016;11:1-22.

22. McCrory C, McNally S. The Effect of Pregnancy Intention on Maternal Prenatal Behaviours and Parent and Child Health: Results of an Irish Cohort Study. Paediatr Perinat Epidemiol. 2013;27:20815.

23. Mohammed F, Musa A, Amano A. Prevalence and determinants of unintended pregnancy among pregnant woman attending ANC at Gelemso General Hospital, Oromiya Region, East Ethiopia: A facility based cross-sectional study. BMC Womens Health. 2016;16:10-6.

24. Ministry of Health NNE and I. Nepal Demographic and Health Survey 2016. Kathmandu, Nepal; 2017.

25. Hall J, Barrett G, Copas A, Stephenson J. London Measure of Unplanned Pregnancy: guidance for its use as an outcome measure. Patient Relat Outcome Meas. 2017;Volume 8:43-56.

26. Habib MA, Raynes-Greenow C, Nausheen S, Soofi SB, Sajid M, Bhutta ZA, et al. Prevalence and determinants of unintended pregnancies amongst women attending antenatal clinics in Pakistan. BMC Pregnancy Childbirth. 2017;17:1-10.

27. Ndziessi G, Bitemo M, Bwira Kaboru B. SM Journal of Community Medicine Gr up SM Unintended Pregnancies and Associated Factors among Contraceptive Users: a Study from Referral Hospitals in Brazzaville, Republic of Congo. SM J Community Med. 2016;2:1015.

28. Tebekaw Y, Aemro B, Teller C. Prevalence and determinants of unintended childbirth in Ethiopia. BMC Pregnancy Childbirth. 2014;14:326.

29. Ikamari L, Izugbara C, Ochako R. Prevalence and determinants of unintended pregnancy among women in Nairobi, Kenya. BMC Pregnancy Childbirth. 2013;13:1.

30. Exavery A, Kanté AM, Njozi M, Tani K, Doctor H V, Hingora A, et al. Predictors of mistimed, and unwanted pregnancies among women of childbearing age in Rufiji, Kilombero, and Ulanga districts of Tanzania. Reprod Health. 2014;11:1-9.

31. Metwally A, Azmy O, Abdelhamed A, Mores C, Salama S, Saleh R, et al. Determinants of unintended pregnancy and its impact on the health of women in some governorates of Upper Egypt. J Arab Soc Med Res. 2015;10:1.

32. Cheraghi P, Poorolajal J, Moeini B, Cheraghi Z. Predictors of unintended pregnancy among married women in hamadan, western Iran: A case-control study. Iran J Public Health. 2013;42:854-9.

33. Izugbara C. Household characteristics and unintended pregnancy among ever-married women in Nigeria. Soc Med. 2014;8:4-10. 
34. Tsegaye AT, Mengistu M, Shimeka A. Prevalence of unintended pregnancy and associated factors among married women in west Belessa Woreda, Northwest Ethiopia, 2016. Reprod Health. 2018;15:1-8.

35. Oulman E, Kim THM, Yunis K, Tamim H. Prevalence and predictors of unintended pregnancy among women: An analysis of the Canadian Maternity Experiences Survey. BMC Pregnancy Childbirth. 2015;15:1-8.

36. Asmare Gite AY. Magnitude and Associated Factors among Pregnant. Reprod Syst Sex Disord. 2015;5:20-5.

37. Gebreamlak W. Magnitude and Factors Influencing Unintended Pregnancy among Pregnant Women Attending Antenatal Care at Felege Hiwot Referral Hospital, Northwest Ethiopia: A Cross-Sectional Study. Sci J Public Heal. 2014;2:261-9.

38. Kamal M, Islam A. Prevalence and socioeconomic correlates of unintented pregnancy among women in rural Bangladesh. Salud Publica Mex. 2011;53:108-15.

39. Eggleston E. Determinants of unintended pregnancy among women in Ecuador. Int Fam Plan Perspect. 1999;25:27-33.

40. Rahman M. Women's autonomy and unintended pregnancy among currently pregnant women in Bangladesh. Matern Child Health J. 2012;16:1206-14.

\section{Figures}




\section{Socio-}

demograph

ic variables

- maternal

age

- age at marriage

- ethnicity

- househol d size

- women's education

- spouse's education

- women's occupatio

$\mathrm{n}$

- spouse's occupatio

$\mathrm{n}$

- autonomy of women

- socioeconomic status
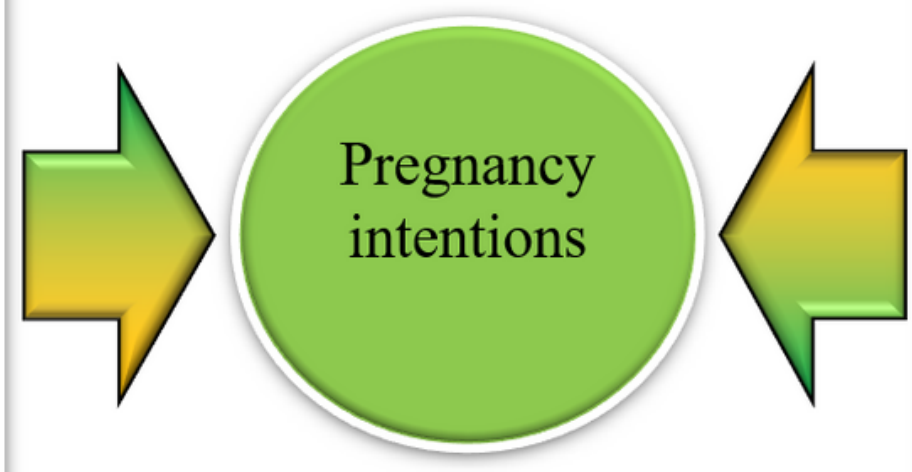

Reproductive health

variables

- number of pregnancy

- parity

- number of abortion

- age of youngest child

- age at first birth

- ideal number of children

- use of family planning

- spousal communicati on

Figure 1

Conceptual Framework of the study 


\title{
Sampling Technique
}

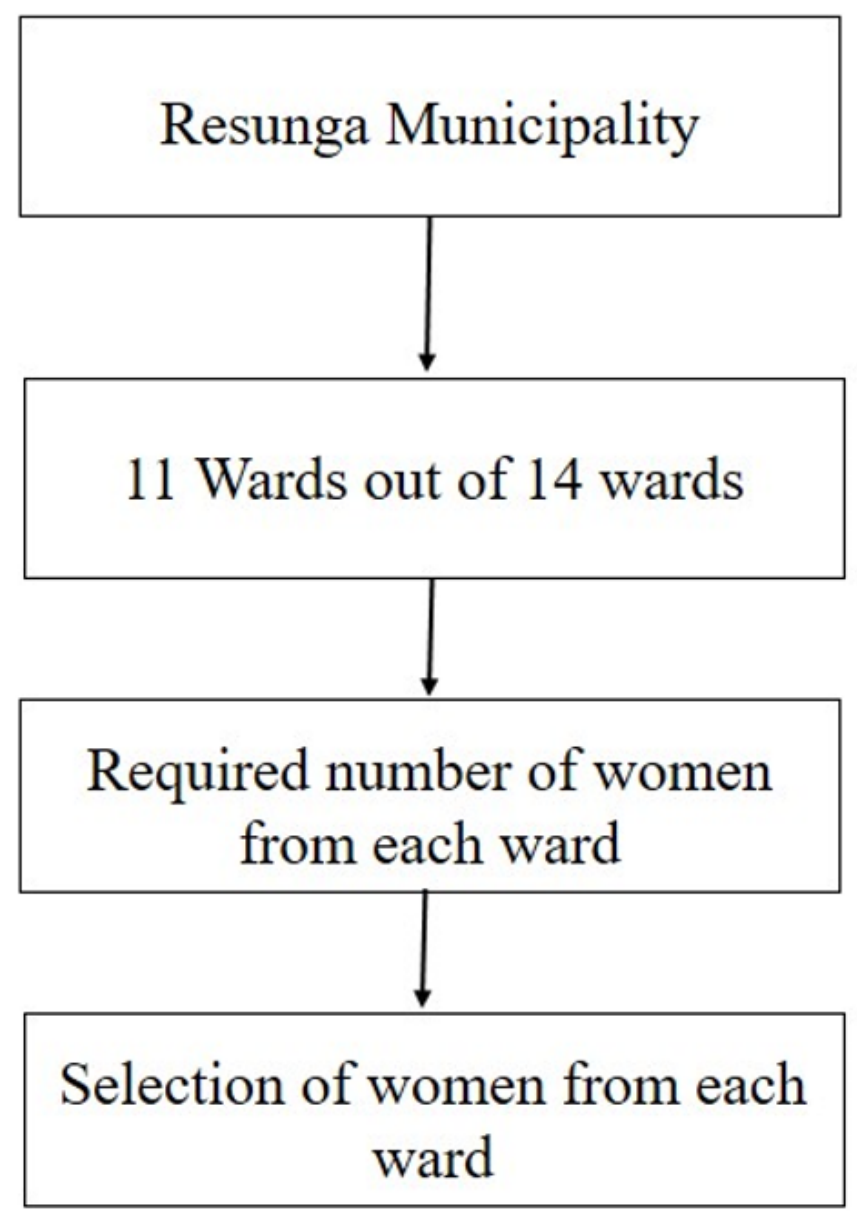

\section{Simple Random Sampling (Lottery)}

Probability Proportion to Size

\author{
Simple Random Sampling \\ (Lottery)
}

Figure 2

Sampling Procedure

\section{Supplementary Files}

This is a list of supplementary files associated with this preprint. Click to download.

- Questionnaire.docx 